\title{
Adult Age Differences in the Benefit of Syntactic and Semantic Constraints for Sentence Processing
}

\author{
Caroline Beese \\ Max Planck Institute for Human Cognitive and Brain Sciences, \\ Leipzig, Germany, and Max Planck Institute for Human \\ Development, Berlin, Germany \\ Ulman Lindenberger \\ Max Planck Institute for Human Development, Berlin, Germany, \\ and Max Planck UCL Centre for Computational Psychiatry and \\ Ageing Research, Berlin, Germany
}

\author{
Markus Werkle-Bergner \\ Max Planck Institute for Human Development, Berlin, Germany \\ Angela D. Friederici and Lars Meyer \\ Max Planck Institute for Human Cognitive and Brain Sciences, \\ Leipzig, Germany
}

\begin{abstract}
Verbal working memory-intensive sentence processing declines with age. This might reflect older adults' difficulties with reducing the memory load by grouping single words into multiword chunks. Here we used a serial order task emphasizing syntactic and semantic relations. We evaluated the extent to which older compared with younger adults may differentially use linguistic constraints during sentence processing to cope with verbal working memory limitations. Probing syntactic-semantic interactions, age differences were hypothesized to be confined to the use of syntactic constraints and to be accompanied by an increased reliance on semantic information. Two experiments varying in verbal working memory demands were conducted: the sequence length was increased from eight items in Experiment 1 to 11 items in Experiment 2. We found the use of syntactic constraints to be compromised with aging, while the benefit of semantic information for sentence processing was comparable across age groups. Hence, we suggest that semantic information processing may become relatively more important for successful sentence processing with advancing adult age, possibly inducing a syntactic-to-semantic-processing strategy shift.
\end{abstract}

Keywords: aging, chunking, semantics, syntax, working memory

It is widely debated whether language processing declines with age (for review, see Shafto \& Tyler, 2014). While aging has been

This article was published Online First October 4, 2018.

Caroline Beese, Department of Neuropsychology, Max Planck Institute for Human Cognitive and Brain Sciences, Leipzig, Germany, and Max Planck Institute for Human Development, Berlin, Germany; Markus Werkle-Bergner, Center for Lifespan Psychology, Max Planck Institute for Human Development; Ulman Lindenberger, Center for Lifespan Psychology, Max Planck Institute for Human Development, and Max Planck UCL Centre for Computational Psychiatry and Ageing Research, Berlin, Germany; Angela D. Friederici and Lars Meyer, Department of Neuropsychology, Max Planck Institute for Human Cognitive and Brain Sciences.

The work of Markus Werkle-Bergner was supported by a grant from the German Research Foundation (WE 4269/5-1), as well as a Jacobs Foundation Research Fellowship. The authors thank Jonas Obleser for advice on data analysis, Fernando Ardente for help with stimulus construction, and Kristiane Klein for help with data acquisition. Preliminary results based on a smaller subsample were presented at a summer school (IMPRS NeuroCom, 2017, London, United Kingdom) when data acquisition was not yet finished. Otherwise, this work has never been presented in full elsewhere.

Correspondence concerning this article should be addressed to Caroline Beese, Department of Neuropsychology, Max Planck Institute for Human Cognitive and Brain Sciences, Stephanstraße 1A, 04103 Leipzig, Germany. E-mail: beese@cbs.mpg.de argued to spare the processing of short or simple sentences (e.g., Gilchrist, Cowan, \& Naveh-Benjamin, 2008; Wingfield, Poon, Lombardi, \& Lowe, 1985), the processing of long or complex sentences deteriorates with age (e.g., Feier \& Gerstman, 1980; Kemper, 1987; Obler, Fein, Nicholas, \& Albert, 1991). This may be related to an age-related decline in verbal working memory (vWM; e.g., Beese, Meyer, Vassileiou, \& Friederici, 2017; Bopp \& Verhaeghen, 2005; Salthouse, 1994) because both long and complex sentences tax vWM (Gibson, 2000; Just \& Carpenter, 1992; Meyer, Obleser, Kiebel, \& Friederici, 2012). The present study investigated whether older adults exploit specific linguistic constraints, that is syntactic regularities and semantic relations, to different extents to counteract their reduced vWM capacities when sentence processing becomes difficult.

Syntactic and semantic constraints on sentence processing have been shown to be employed differentially across the life span (e.g., Friederici, Schriefers, \& Lindenberger, 1998). Comparing syntactic and semantic processing directly, it was found that syntactic, but not semantic, processing was deficient in older, relative to younger adults (Friederici et al., 1998). Other studies investigating either syntactic or semantic processing in elderly people support this finding: Syntactic processing speed and accuracy are lower in older compared with younger adults when processing demands are high; for example, when processing syntactically long, ambiguous, or complex sentences (e.g., Kemper, 1986; Kemper, Crow, \& 
Kemtes, 2004; Obler et al., 1991, respectively). In comparison, lexical-semantic processing speed and accuracy do not appear to differ between younger and older adults (e.g., Burke, White, \& Diaz, 1987; Gunter, Jackson, \& Mulder, 1998; Laver, 2009). In addition, the results of numerous studies document adult age differences in online sentence processing heuristics during selfpaced reading (Radvansky, 1999; Radvansky, Curiel, Zwaan, \& Copeland, 2001; Radvansky \& Dijkstra, 2007; Stine, 1990; StineMorrow, Loveless, \& Soederberg, 1996; Stine-Morrow, Noh, \& Shake, 2010). Specifically, older adults allocate fewer resources than younger adults to the decoding of orthographic or syntactic features (i.e., the surface form) or to the conceptual integration of words into coherent syntactic constituents conveying propositional content (i.e., the textbase). Rather, older adults focus on the creation of the mental representation of the events described (i.e., the situation model). Hence, older adults may rely more on semantic than syntactic constraints to successfully process sentences.

Insufficient resources, in particular verbal working memory limitations as a domain-general processing resource (Gibson, 2000; Just \& Carpenter, 1992; Meyer et al., 2012), may impair older adults' engagement in enriched sentence processing (e.g., Christianson, Williams, Zacks, \& Ferreira, 2006). Generally, the verbatim surface form and textbase information (i.e., syntactic regularities and propositional content, respectively) are remembered for shorter intervals than the situation model of sentences (i.e., the overall event described; Kintsch, Welsch, Schmalhofer, \& Zimny, 1990; Sachs, 1967). Particularly, in older adults, representations of surface form or textbase information fade away even more rapidly (e.g., Radvansky et al., 2001). Hence, it seems plausible to assume that advancing adult age is accompanied by a shift in processing heuristics. According to this proposal, older adults allocate fewer resources to an enriched decoding of surface form or textbase information and more resources to the situation model than do younger adults (e.g., Stine-Morrow et al., 1996). This processing heuristic may help older adults to reduce demands on resources that would otherwise be unavailable if already consumed by these lower level processes.

Syntactic and semantic constraints can be helpful to reduce vWM costs during sentence processing. That is, discrete words can be grouped into multiword phrases based on syntactic regularities and semantic relations (e.g., Bonhage, Meyer, Gruber, Friederici, \& Mueller, 2017; Epstein, 1962). This grouping, henceforth chunking, increases the amount of information stored in working memory (Gilchrist, 2015; Gilchrist \& Cowan, 2012; Gobet et al., 2001; Gobet, Lane, \& Lloyd-Kelly, 2015; Miller, 1956). On the one hand, words can be grouped together on the basis of syntactic regularities (e.g., word categories, word order); for example, the function word "the" with the content word "boat" into the multiword phrase "the boat" (e.g., Bonhage et al., 2017; Meyer, Henry, Gaston, Schmuck, \& Friederici, 2017; Schell, Zaccarella, \& Friederici, 2017). When words are grouped together by syntactic regularities, they are remembered better than words that cannot be grouped together in this way (the so-called sentence superiority effect, e.g., Baddeley, Hitch, \& Allen, 2009; Bonhage, Fiebach, Bahlmann, \& Mueller, 2014; Bonhage et al., 2017; Cattell, 1886; Snell \& Grainger, 2017). From now on, we call this grouping process syntactic chunking. The term denotes the abstract binding of words' syntactic categories, which has been argued to occur rather automatically, unconsciously, and without any strategic efforts (Baddeley et al., 2009; Freudenthal, Pine, Aguado-Orea, \& Gobet, 2007; Gobet, Lloyd-Kelly, \& Lane, 2016). In the previous example, the binding of "the" and "boat" is based on syntactic not semantic information, creating a two-word phrase without building up a semantic representation that would go beyond the word-level meaning. Similarly, multiple content words like "sleepy" and "boat" may also be grouped together based on syntactic information. However, this can result in a semantically anomalous phrase, like "sleepy boat," when the content words are not semantically related. But when words can indeed be grouped together based on semantic information (e.g., semantic relatedness), then enriched semantic representations are formed. For example, the content words "wooden" and "boat" may be grouped together into one joint representation of a "wooden boat" creating an enriched semantic representation of "boat" (Schell et al., 2017). This is conventionally known as conceptual chunking (Bierwisch \& Schreuder, 1992; Miller, 1956).

Age differences in the chunking of word sequences have been found in studies examining either online, real-time processing (for an overview, see Stine-Morrow \& Payne, 2016) or poststimulus, offline effects (Gilchrist et al., 2008); yet, the online and offline results differ. On the one hand, online studies suggest that older adults generate smaller chunks to accommodate their vWM capacity limitations, reflected in a greater allocation of processing resources to intrasentence compared with intersentence boundaries (e.g., Stine, 1990; Stine-Morrow et al., 2010). On the other hand, offline studies suggest that older adults remember fewer, but not smaller chunks than younger adults. For instance, Gilchrist et al. (2008) manipulated both memory load (i.e., number of unrelated sentences) and chunk size (i.e., number of clauses), reporting age differences during verbatim recall with respect to the former but not to the latter. There are several relevant differences between previous online and offline studies. First, online and offline studies assessed chunking differently: Online studies inferred chunking on the basis of reading or gaze time measurements, while offline studies assessed chunking by enhancing or reducing opportunities for chunking in the experimental material. Second, online studies dissociated syntactic and semantic information processing via statistical means, rather than via experimental manipulations; the offline studies did not dissociate the contribution of these distinct linguistic information types on chunking at all. However, no study to date has assessed age differences in the extent to which different linguistic information types are used for chunking, neither online nor offline. To clarify this open question, our study aimed at dissociating the extent to which older adults differentially use syntactic and semantic constraints for chunking during sentence processing to circumvent their vWM limitations, using an offline task.

Syntactic chunking has been shown to occur independently of semantic information processing in younger adults (Epstein, 1962); however, this may change with increasing syntactic processing deficits across the life span. Here, we manipulate the availability of syntactic and semantic constraints for chunking during sentence processing in younger and older adults. We employed sentences that pose lower (Experiment 1) or higher (Experiment 2) vWM demands through varying the sequence length. Syntactic chunking was assessed through the classical comparison of multiword syntactic phrases versus random word lists (Baddeley et al., 2009). To assess semantic information processing, we 
adapted the classical dissociation of meaningful versus meaningless words by comparing real words to pseudowords (e.g., Cattell, 1886; Epstein, 1962; Reicher, 1969). We used an offline serial order task to assess processing success for verbal materials that vary in the availability of syntactic and semantic constraints. The presence of those linguistic constraints facilitated or hampered chunking and therefore the accommodation of vWM limitations. We hypothesized that older adults do not use syntactic constraints as much as younger adults during the processing of longer sentences, because vWM-intensive sentence processing is known to deteriorate with age (e.g., Kemper, 1986; Kemper et al., 2004; Obler et al., 1991). Furthermore, because of this disadvantage in syntactic chunking, we expected a stronger reliance on semantic constraints in older participants. This is in line with previous studies suggesting a syntactic-to-semantic processing strategy shift in the elderly (e.g., Amichetti, White, \& Wingfield, 2016). Systematically varying the availability of syntactic and semantic constraints during sentence processing, the results showed that the advantage of remembering the temporal order of words in sentences over lists was reduced in older compared with younger adults, in particular when sentences were longer, and thus highly vWM-demanding (Experiment 2). This observation indicates that syntactic constraints may not be used as much by older compared with younger adults. While the presence of syntactic constraints was more beneficial for younger than older adults, the benefit of the presence of semantic constraints was comparable across age groups.

\section{Experiment 1}

Previous literature suggests that older adults have difficulties processing vWM-intensive sentences (e.g., Beese et al., 2017; Kemper, 1986, 1987; Wingfield et al., 1985). The extent to which the presence of syntactic regularities benefits vWM-intensive sentence processing, by enabling syntactic chunking und thereby reducing the vWM load, can be indexed through the sentence superiority effect (Baddeley et al., 2009). Age differences in the sentence superiority effect have been found more pronounced in eight-word sequences (Wingfield et al., 1985). Specifically, it has been shown that older adults repeat five- and eight-word sentences as accurately as younger adults. However, older but not younger adults' repetition accuracy is poorer for eight-word but not fiveword lists. Therefore, in Experiment 1, meaningful and meaning- less lists and sentences of eight words were compared. We aimed at dissociating the contribution of syntactic from semantic constraints to age differences in sentence processing.

\section{Method}

Participants. Fifty-six healthy right-handed native speakers of German, divided into two equally sized age groups (younger vs. older adults), participated for a reimbursement of $9 €$ per hour. After outlier removal (see Experiment 1 - Statistical analysis), the data of 27 younger adults (13 men, age range $=20-31$ years, mean age $=25.67$ years, $S D$ age $=2.56$ years $)$ and 26 older adults (12 men, age range $=62-71$ years, mean age $=66.35$ years, $S D$ age $=2.40$ years) were analyzed. All participants had normal or corrected-to-normal vision and did not suffer from any neurological disorders according to self-report. The age groups were matched for their level of education (i.e., they had at least a high-school diploma or an equivalent; for more details, see Table 1). Prior to the experiment, all participants gave written informed consent. The experiment was approved by the ethics committee of the University of Leipzig. The experiment was conducted in accordance to the Declaration of Helsinki.

Verbal working memory measures. To assess potential associations of age differences in $\mathrm{vWM}$ with sentence processing (e.g., Bopp \& Verhaeghen, 2005; Lewis, Vasishth, \& Van Dyke, 2006; Salthouse, 1994), we acquired three additional standardized measures. Two of those measured particularly the storage component of vWM, or otherwise short-term memory (STM) capacity (i.e., the digit span task forward; Aster, Neubauer, \& Horn, 2006; and the nonword repetition span task; Welte, 1981). One further test assessed both the storage as well as the manipulation component (i.e., the digit span task backward; Aster et al., 2006). Given that the three tests of vWM showed a moderate degree of common variance $(\alpha=.69)$, we combined the test scores into one composite score (see Experiment 1 - Statistical analysis). The test results are reported in Table 1. For 18 participants (12 younger, 6 older adults), these tests were acquired for the current study in this order; for all other participants, the test results were available from a previous study (mean delay $=13$ months; $S D$ delay $=1$ month; Beese et al., 2017).

Stimuli. The study design (Table 2 ) followed a $2 \times 2$ design with the factors sentence structure (sentences vs. word lists) and meaning (real words vs. pseudowords).

Table 1

Demographics and Individual Differences: Summary of Experiment 1 and 2

\begin{tabular}{|c|c|c|c|c|c|c|c|c|c|c|c|c|}
\hline \multirow[b]{3}{*}{ Measure } & \multicolumn{6}{|c|}{ Experiment 1} & \multicolumn{6}{|c|}{ Experiment 2} \\
\hline & \multicolumn{2}{|c|}{ Young $(n=27)$} & \multicolumn{2}{|c|}{ Old $(n=26)$} & \multirow[b]{2}{*}{$t$} & \multirow[b]{2}{*}{$p$} & \multicolumn{2}{|c|}{ Young $(n=26)$} & \multicolumn{2}{|c|}{ Old $(n=27)$} & \multirow[b]{2}{*}{$t$} & \multirow[b]{2}{*}{$p$} \\
\hline & $M$ & $S D$ & $M$ & $S D$ & & & $M$ & $S D$ & $M$ & $S D$ & & \\
\hline \multicolumn{13}{|l|}{ Demographics } \\
\hline Age & 25.67 & 2.56 & 66.35 & 2.40 & & & 25.12 & 3.24 & 64.19 & 2.76 & & \\
\hline Education & 17.56 & 1.99 & 17.92 & 1.98 & -.67 & .50 & 18.08 & 2.76 & 16.63 & 2.45 & 2.02 & .05 \\
\hline \multicolumn{13}{|l|}{ Memory } \\
\hline Digit span forward & 10.81 & 2.29 & 9.85 & 1.59 & 1.79 & .08 & 10.73 & 1.43 & 9.59 & 1.82 & 2.53 & .01 \\
\hline Digit span backward & 8.70 & 2.27 & 6.15 & 1.54 & 4.80 & $1.70 \times 10^{-5}$ & 8.62 & 2.55 & 6.59 & 1.42 & 3.55 & $1.02 \times 10^{-3}$ \\
\hline Repetition span & 27.93 & 3.00 & 25.62 & 3.59 & 2.54 & .01 & 26.69 & 3.33 & 25.15 & 4.83 & 1.36 & .18 \\
\hline Composite score & .37 & .72 & -.38 & .66 & 3.94 & $2.50 \times 10^{-4}$ & .33 & .73 & -.37 & .77 & 3.11 & $3.00 \times 10^{-3}$ \\
\hline
\end{tabular}


Table 2

Experiment 1, Example of Stimulus Material: Meaningful Sentences (Structure+, Meaning+), Meaningful Word Lists (Structure-, Meaning+), Meaningless Sentences (Structure + Meaning-), and Meaningless Word Lists (Structure-, Meaning-)

\begin{tabular}{lll}
\hline \multirow{2}{*}{ Meaning } & \multicolumn{1}{c}{ Structure } \\
\cline { 2 - 3 } Real words & $\begin{array}{l}\text { Sentences } \\
\text { der Opa verdarb die Suppe mit dem Salz }\end{array}$ & $\begin{array}{l}\text { Lists der dem Suppe mit Opa Salz die verdarb } \\
\text { the the soup with granddad salt the ruined } \\
\text { Pseudowords }\end{array}$ \\
$\begin{array}{l}\text { der Apo verworb die Junne mit dem Sohr } \\
\text { the Apo verworb the Junne with the Sohr }\end{array}$ & $\begin{array}{l}\text { der dem Junne mit Apo Sohr die verworb } \\
\text { the the Junne with Apo Sohr the verworb }\end{array}$ \\
\hline
\end{tabular}

Stimuli consisted of eight items; that is, words or pseudowords. All sentence conditions had a consistent syntactic structure (e.g., [[der Opa] [verdarb [die Suppe] [mit dem Salz]]]; the granddad ruined the soup with the salt). The eight items spanned three phrases connected through the verb. Meaningless sentence conditions were created by keeping function words in place while replacing content words with pseudowords (e.g., [[der Apo] [verworb [die Junne] [mit dem Sohr]]]; the apo verworbed the junne with the sohr). Pseudowords were generated based on the real content words using Wuggy (Keuleers \& Brysbaert, 2010), matching the original words in syllable length and syllable transition frequency. Each content word and pseudoword was unique across the whole stimulus set. List conditions were created by permuting all items of each sentence, keeping the lexical information equal across real word conditions (e.g., real word list: der dem Suppe mit Opa Salz die verdarb; the soup with granddad salt the ruined). Permutation patterns were identical across the real word and pseudoword conditions (e.g., pseudoword list: der dem Junne mit Apo Sohr die verworb; the junne with apo sohr the verworbed). To avoid syntactic phrase formation, a number of permutation patterns were excluded (verb-noun, verb-determiner, noun-verb, and verbpreposition; cf. Brennan et al., 2012). This reduced opportunities for syntactic chunking in list conditions. However, because of the flexible word order in German, less common partial phrases were inevitable (e.g., die verdarb could, in another context, also be part of a relative clause). Nevertheless, list conditions constituted a stark contrast to the sentence conditions in terms of the availability of syntactic regularities used for syntactic chunking. To avoid encoding differences introduced by the stimulus onset across conditions, the first item was always a lower-case determiner.

The permutation of real word sentences into real word lists aimed at dissolving information provided by the syntactic structure, while preserving the lexical meaning. Yet, the permutation could have induced a confound to our manipulation of lexical meaning. That is because each incoming word adds to the amount of lexical-semantic information of the current context, in both real word sentences and lists. We controlled for any differences in the amount of lexical-semantic information provided by the context, between real word sentences and lists, by employing the lexical surprisal metric (e.g., Hale, 2001), a computational measure of a word's unexpectedness given a current context. Specifically, differences in surprisal between real word sentences and lists were minimized to an absolute z-transformed surprisal value smaller than 2. To this end, a freely available lexicalized top-down leftcorner parser (Roark, Bachrach, Cardenas, \& Pallier, 2009), trained on the TIGER Treebank (Brants et al., 2004), was employed. To control for effects of animacy (Bonin, Gelin, \& Bugaiska, 2014), half of the subjects were animate, half inanimate. To account for possible differences in lexical access demands, word length (i.e., syllable count $=1-3$ syllables per word; Spoehr $\&$ Smith, 1973) and word frequency (i.e., frequency class $=8-$ 15; Goldhahn, Eckart, \& Quasthoff, 2012; Halgren et al., 2002) were constrained in range across items to control for variability. According to these criteria, 96 sequences in the four conditions were created, resulting in a total pool of 384 stimuli.

Participants' ability to use syntactic chunking and semantic information to facilitate $\mathrm{vWM}$-intensive sentence processing was evaluated via a serial order task (Bonhage et al., 2014, 2017): After each stimulus, participants were asked to judge whether the order of two items from the last stimulus matched the order of presentation. For example, after the stimulus der Opa verdarb die Suppe mit dem Salz, the participants may have been asked: Did the word Opa come before the word mit? (abbreviated on screen as Opa $<<<$ mit). Probing the serial order position emphasized the decoding of syntactic regularities and semantic relations during sentence processing. A total of eight different questions were created for each stimulus, querying any pair of items that were divided by three other items. The prompted words were always selected from different phrases in sentence conditions, assuring similar retrieval difficulty compared with list conditions (Johnson, 1978). For half of those questions, the correct answer was yes, for the other half no. The assignment of questions resulted in a total of 3,072 stimulus-question combinations.

The total set of stimulus-question combinations was distributed across 16 stimulus lists of 192 stimuli each; thus, each stimulus list contained always two conditions (one real word condition, one pseudoword condition) out of one set of the four conditions. The question assignment was counterbalanced within lists across sequences and across sequences across lists. In addition, the sequences of each stimulus list were pseudorandomized such that no condition, question, answer type or animate subject occurred consecutively more than four to five times and such that the two conditions of the same stimulus were always separated by at least 20 other sequences.

Procedure. Before the experiment, participants were informed about the four experimental conditions and the task. Stimuli were presented visually, item by item, for $600 \mathrm{~ms}$ per item, in white, nonserif letters (Arial, font size $30 \mathrm{pt}$ ) in the center of the screen (Sony, Trinitron, 17 in., $60 \mathrm{~Hz}$ refresh rate) on a gray background. The stimulus presentation was followed by a fixation 
cross of 2,500 ms, followed by a question probing serial order position. Participants had a time limit of $8 \mathrm{~s}$ to answer the question with either yes or no by pressing either of two buttons on a button box. Button assignment was counterbalanced across participants. After the response, participants were provided with visual feedback (happy or sad emoticon) for $400 \mathrm{~ms}$. An intertrial interval of 2,500 ms followed each trial. A practice session of eight trials familiarized participants with the procedure. At five equally distributed points across the experiment, participants could take a break of a maximum of $4 \mathrm{~min}$.

Statistical analysis. For statistical analyses, d-prime $\left(d^{\prime}\right)$ scores were calculated from participants' yes and no responses to the yes-correct and no-correct questions; after reaction time (RT) outliers (i.e., RTs outside the range of the median RT $+/-2.5$ median absolute deviations (MADs; Leys, Ley, Klein, Bernard, \& Licata, 2013), and missing responses were removed (both constituted on average $1.68 \%$ per participant, $S D=1.66 \%$ ). $d^{\prime}$ scores account for participants' inherent response bias (Macmillan \& Creelman, 2005) and are computed by subtracting the z-transformed false-alarm rate (FA; i.e., yes responses to nocorrect questions) from the $\mathrm{z}$-transformed hit rate $(\mathrm{H}$; i.e., yesresponses to yes-correct questions). $\mathrm{H}$ and FA of 0 were corrected by $1 /(N+1)$, while $\mathrm{H}$ and FA of 1 were corrected by $(N-1) / \mathrm{N}$, whereby $N$ is the number of trials (Macmillan \& Creelman, 2005). Within each age group, participants who performed below chance (i.e., $d^{\prime}<0$, two older adults), as well as those which constituted group outliers (i.e., $d^{\prime}>2 S D$, one younger adult and the same two older below chance performers) were excluded from further analyses (in total three participants).

$d^{\prime}$ scores were subjected to a three-way analysis of variance (ANOVA), including the within-participants factors sentence structure (sentences vs. word lists) and meaning (real words vs. pseudowords) and the between-participants factor age group (younger vs. older adults). To assess a potential influence of age differences in vWM capacity (Bopp \& Verhaeghen, 2005) on $d^{\prime}$ scores, the three additionally acquired memory measures were first z-transformed across both age groups simultaneously and then averaged into one composite score in order to be later included as a between-subjects covariate into an analysis of covariance (ANCOVA). Any interaction effects were broken down with simple effects analysis, controlling for multiple comparisons with Bonferroni correction.

Post hoc, we dissociated the impact of the availability of syntactic and semantic constraints for chunking from mere effects of syntactic and lexical predictability; in principle, participants' memory retrieval success could depend on the syntactic or lexical probability of a word to occur within a prior sentence. To assess this potential confound, we computed the lexical-semantic and syntactic predictabilities of the word that was to be retrieved for a given trial, using computational-linguistic methodology (for more details on the calculation of these measures, see Meyer \& Gumbert, 2018; Roark et al., 2009). For example, for the question Did the word Opa come before the word mit?, predictabilities of the word Opa (granddad) of the prior sentence der Opa verdarb die Suppe mit dem Salz (the granddad ruined the soup with the salt) were computed. This procedure was repeated for all trials of the structured and meaningful condition. For each participant, both accuracy and surprisal values were then averaged across trials within word position. Across word positions, within participants, we then calculated correlations between accuracy and surprisal values, reasoning that if retrieval demands were confounded with predictability, predictability should significantly correlate with accuracy. Across participants, we corrected the test statistics for multiple comparisons using the False Discovery Rate (FDR) procedure.

\section{Results}

The three-way ANOVA (sentence structure $\times$ meaning $\times$ age group) on the $d^{\prime}$ values showed three main effects: sentence structure, $F(1,51)=182.95, p=2.20 \times 10^{-16}, \eta^{2}=.39$; meaning, $F\left(1,51=57.79, p=6.12 \times 10^{-10}, \eta^{2}=.06\right.$; and age group, $F(1,51)=6.88, p=1.15 \times 10^{-2}, \eta^{2}=.09$. Figure 1 shows an overview of the single subject and group mean (young vs. old) $d^{\prime}$ values for each condition (real word sentences, pseudoword sentences, real word lists, and pseudoword lists). Table 3 shows an overview of all response types (hit, miss, false alarm, and correct rejection rates) for Experiment 1 and 2 across age groups.

More precisely, performance for sentences $(M=3.20, S D=$ 1.42) was higher than for lists $(M=1.54, S D=0.79)$. Performance for meaningful stimuli $(M=2.65, S D=1.51)$ was higher than for meaningless stimuli $(M=2.10, S D=1.28)$. Younger adults performed better $(M=2.69, S D=1.42)$ than older adults $(M=2.04, S D=1.35)$. Furthermore, an interaction effect was found between structure and meaning, $F(1,51)=17.80, p=$ $1.00 \times 10^{-4}, \eta^{2}=.02$. Simple effects analysis (Bonferronicorrected) showed that while performance was significantly higher for meaningful sentences $(M=3.64, S D=1.40)$ than meaningless sentences $(M=2.77, S D=1.32) ; t(102)=-8.33, p=1.55 \times$

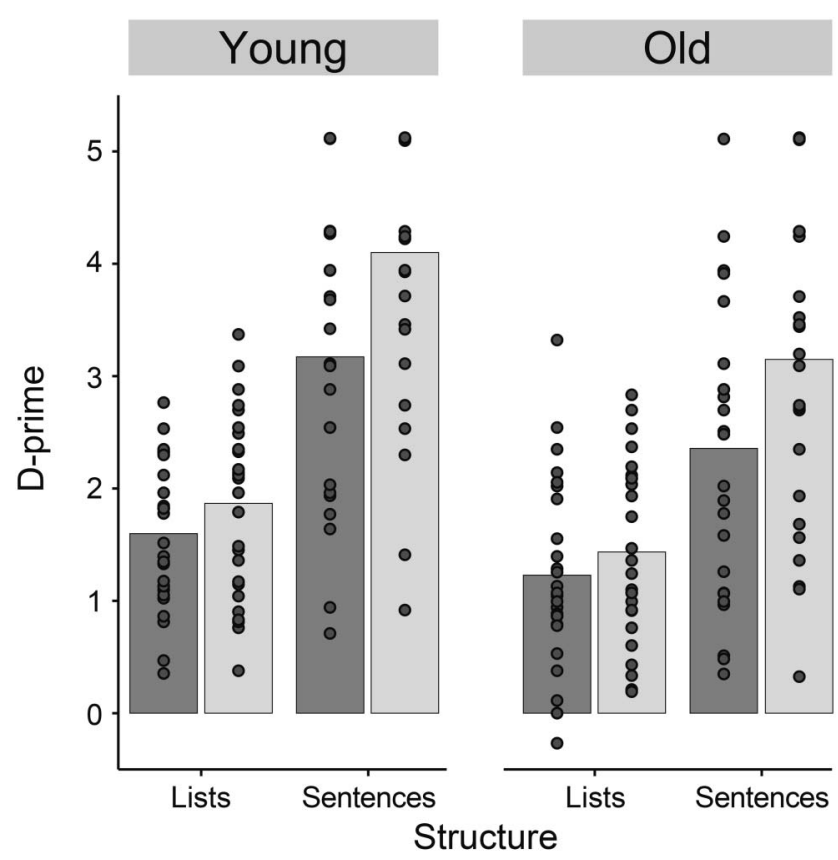

Meaning: $\square$ Pseudowords $\quad \square$ Real words

Figure 1. Experiment 1, trending age differences in syntactic (sentences vs. lists) but not semantic (real words vs. pseudowords) processing. 
Table 3

Mean and SD Hit (H), Miss (MISS), False Alarm (FA), and Correct Rejection (CR) Rates for Each Condition and Age Group: Summary of Experiment 1 and 2

\begin{tabular}{|c|c|c|c|c|c|c|c|c|c|c|c|c|c|c|c|c|}
\hline \multirow[b]{3}{*}{ Condition } & \multicolumn{8}{|c|}{ Young } & \multicolumn{8}{|c|}{ Old } \\
\hline & \multicolumn{2}{|c|}{$\mathrm{H}$} & \multicolumn{2}{|c|}{ MISS } & \multicolumn{2}{|c|}{ FA } & \multicolumn{2}{|c|}{$\mathrm{CR}$} & \multicolumn{2}{|c|}{$\mathrm{H}$} & \multicolumn{2}{|c|}{ MISS } & \multicolumn{2}{|c|}{ FA } & \multicolumn{2}{|c|}{$\mathrm{CR}$} \\
\hline & $M$ & $\overline{S D}$ & $M$ & $\overline{S D}$ & $M$ & $\overline{S D}$ & $M$ & $\overline{S D}$ & $M$ & $\overline{S D}$ & $M$ & $\overline{S D}$ & $M$ & $\overline{S D}$ & $M$ & $S D$ \\
\hline \multicolumn{17}{|l|}{ Experiment 1} \\
\hline \multicolumn{17}{|l|}{ Sentences } \\
\hline Real words & .96 & .07 & .04 & .07 & .06 & .10 & .94 & .10 & .89 & .13 & .11 & .13 & .11 & .15 & .89 & .15 \\
\hline Pseudowords & .91 & .10 & .09 & .10 & .10 & .11 & .90 & .11 & .86 & .13 & .14 & .13 & .20 & .16 & .80 & .16 \\
\hline \multicolumn{17}{|l|}{ Lists } \\
\hline Real words & .85 & .09 & .15 & .09 & .26 & .14 & .74 & .14 & .77 & .14 & .23 & .14 & .29 & .15 & .71 & .15 \\
\hline Pseudowords & .81 & .09 & .19 & .09 & .27 & .15 & .73 & .15 & .77 & .17 & .23 & .17 & .37 & .12 & .63 & .12 \\
\hline \multicolumn{17}{|l|}{ Experiment 2} \\
\hline \multicolumn{17}{|l|}{ Sentences } \\
\hline Real words & .93 & .08 & .07 & .08 & .12 & .10 & .88 & .10 & .87 & .10 & .13 & .10 & .24 & .11 & .76 & .11 \\
\hline Pseudowords & .83 & .09 & .17 & .09 & .23 & .15 & .77 & .15 & .74 & .14 & .26 & .14 & .39 & .17 & .61 & .17 \\
\hline \multicolumn{17}{|l|}{ Lists } \\
\hline Real words & .73 & .11 & .27 & .11 & .34 & .16 & .66 & .16 & .74 & .11 & .26 & .11 & .50 & .10 & .50 & .10 \\
\hline Pseudowords & .73 & .08 & .27 & .08 & .36 & .15 & .64 & .15 & .72 & .11 & .28 & .11 & .51 & .11 & .49 & .11 \\
\hline
\end{tabular}

$10^{-12}$, this performance difference was not present for meaningful lists $(M=1.66, S D=0.82)$ compared with meaningless lists $(M=$ $1.42, S D=0.75) ; t(102)=-2.30, p=.09$. Moreover, simple effects analysis showed a performance advantage for sentences over word lists, with real words, $t(84)=-13.77, p=1.35 \times$ $10^{-22}$, and also with pseudowords, $t(84)=-9.42, p=3.50 \times$ $10^{-14}$, indicating a sentence superiority effect independent of meaningfulness. A direct comparison showed that the advantage of sentence structure was significantly higher within meaningful stimuli (mean $d^{\prime}$ difference $=1.98, S D=1.12$ ) than within meaningless stimuli (mean $d^{\prime}$ difference $=1.36, S D=0.99$ ); $t(52)=8.58, p=1.96 \times 10^{-15}$. No other significant effects were observed (all $F<0.48$, all $p>.49$ ), but there was a trending interaction effect between sentence structure and age group, $F(1$, $51)=3.84, p=.056, \eta^{2}=.01$. Simple effects analysis showed that while performance for sentences was significantly higher in younger adults $(M=3.64, S D=1.31)$ than older adults $(M=$ $2.75, S D=1.40) ; t(75)=3.22, p=7.50 \times 10^{-3}$, performance for lists did not differ between younger adults $(M=1.73, S D=0.73)$ and older adults $(M=1.33, S D=0.81) ; t(75)=1.47, p=.59$. Accordingly, the performance advantage for sentences over lists tended to be larger in younger adults (mean $d^{\prime}$ difference $=1.77$, $S D=0.79$ ) than in older adults (mean $d^{\prime}$ difference $=1.29, S D=$ $0.90) ; t(50)=2.07, p=.04$. Yet, because the interaction between age group and sentence structure was only marginally significant, this is not strong evidence for an enlarged sentence superiority effect for younger adults.

The trending interaction effect between age group and sentence structure may have also come about because of age differences in vWM capacity (Table 1). Therefore, the composite score of the vWM measures was included as between-subjects covariate into an ANCOVA. The results showed the same main effects for sentence structure, $F(1,50)=179.39, p=2.20 \times 10^{-16}, \eta^{2}=$ .41 , and meaning, $F(1,50)=56.67, p=8.98 \times 10^{-10}, \eta^{2}=.07$, whereas the main effect for age group was not significant anymore. While the interaction effect between sentence structure and meaning, $F(1,50)=18.12, p=9.01 \times 10^{-5}, \eta^{2}=.02$, persisted, the trending interaction between age group and structure did not continue to differ significantly from zero. No other effects turned out significant (all $F<2.31$, all $p>.13$ ), indicating no robust disadvantage for older compared with younger adults despite older adults' vWM limitations.

Finally, the additional post hoc analysis controlling for predictability effects revealed that neither syntactic (median rho across participants $=-0.04$, quartile $1[\mathrm{Q} 1]=-0.27$, quartile $3[\mathrm{Q} 3]=$ 0.10 , all FDR-corrected $p>99$ ) nor lexical conditional probabilities (median rho across participants $=0.16, \mathrm{Q} 1=-0.26, \mathrm{Q} 3=$ 0.30 , all FDR-corrected $p>.78$ ) could explain the role of the availability of syntactic and semantic constraints for chunking, respectively.

\section{Discussion}

In line with previous studies, Experiment 1 demonstrated an overall lower performance in older adults' sentences processing. We did not observe a specific benefit of available semantic information during sentence processing in the older adults. Moreover, it remains unclear whether the reduced performance could be associated with specific age differences in syntactic processing because only a trending interaction with age group was apparent. We hypothesized that the nonsignificance of this effect reflects relatively low processing difficulty: possibly, the reliance on syntactic constraints as an encoding strategy to circumvent capacity limits may only become evident when sentence processing is even more capacity-demanding. Therefore, in Experiment 2, the length of the original eight-item stimuli was increased by three items.

\section{Experiment 2}

The overarching aim of Experiment 2 was to further increase the sensitivity in dissociating the respective contributions of syntactic and semantic constraints to age differences in vWM-intensive sentence processing. To this end, vWM demands were increased 
by increasing the sequence length from 8 to 11 items. In addition, interindividual $\mathrm{vWM}$ capacity differences were assessed to further dissociate language-specific from domain-general constraints of sentence processing.

\section{Method}

Participants. Participant recruitment followed that of Experiment 1 in all aspects; that is, health, handedness, education, consent, and approval of conduction. From a total of 56 participants, after outlier removal (see Experiment 2 - Statistical analysis), the sample consisted of 26 younger (13 men, age range $=20-$ 32 years, mean age $=25.12$ years, $S D$ age $=3.24$ years) and 27 older adults $(13$ men, age range $=60-70$ years, mean age $=$ 64.19 years, $S D$ age $=2.76$ years $)$.

Verbal working memory measures. As for Experiment 1, all participants underwent the same STM and vWM measures in the same order (Table 1). The scores were then combined into a composite score ( $\alpha=.73$; see Experiment $1-$ Statistical analysis).

Stimuli. The experimental design of Experiment 2 resembles the design of Experiment 1 (Table 4). However, to increase participants' reliance on sentence structure and meaning to reduce their overall memory load, the stimulus length was increased to 11 items by adding one phrase of three additional words or pseudowords (e.g., real word sentence: der Opa verdarb die Suppe mit dem Salz trotz des Rezepts; the granddad ruined the soup with the salt despite the recipe; e.g., pseudoword sentence: der Apo verworb die Junne mit dem Sohr trotz des Rezerms; the apo verworbed the junne with the sohr despite the rezerms; added phrase underlined). Because of the increased number of items, the permutation patterns of the list conditions were created anew, excluding verb-noun, verb-determiner, verb-determiner-noun, noun-verb, verb-noun-preposition, noun-preposition-noun, and prepositionnoun-noun (cf. Brennan et al., 2012). All other criteria were reapplied. In addition, we also controlled for differences in the variability of the sentence length (i.e., the total syllable count of all words) between Experiment 1 and 2, $F(95,83)=0.72, p=.11$.

The experimental task design was the same as in Experiment 1. However, querying any two items that were divided by three other items in 11-item sequences increased the set of questions to 14 . Therefore, to balance the stimulus-question assignment, a subset of 84 sequences in all four conditions were selected from Experiment 1 (i.e., 336 stimuli in total). This created a total of 4,704 stimulus-question combinations which were distributed across 28 stimulus lists with 168 stimuli each. Other randomization criteria from Experiment 1 were reapplied with the only difference being the consecutive occurrences of stimulus features which were increased to five to seven times. Also, the two conditions of the same stimulus were separated by at least five other sequences.

Procedure. The procedure of Experiment 2 was identical to that of Experiment 1.

Statistical analysis. The behavioral measures as well as the statistical analyses in Experiment 2 were identical to those of Experiment 1. In Experiment 2, two younger and one older participant were removed as group outliers (i.e., $d^{\prime}>2 S D$; there were no below chance performers). Furthermore, RT outliers (for detection criteria, see Experiment 1-Statistical analysis) and missing responses constituted on average $1.60 \%(S D=1.68 \%)$ per participant.

\section{Results and Discussion}

Similar to the results of Experiment 1, the three-way ANOVA (sentence structure $\times$ meaning $\times$ age group) showed three main effects: sentence structure, $F(1,51)=181.42, p=2.20 \times 10^{-16}$, $\eta^{2}=.41$, meaning, $F(1,51)=62.66, p=1.97 \times 10^{-10}, \eta^{2}=.15$, and age group, $F(1,51)=22.69, p=1.62 \times 10^{-5}, \eta^{2}=.19$. Figure 2 shows an overview of the single subject and group mean (young vs. old) $d^{\prime}$ values for each condition (real word sentences, pseudoword sentences, real word lists, and pseudoword lists).

More precisely, performance for sentences $(M=2.02, S D=$ 1.12) was higher than for lists $(M=0.85, S D=0.57)$. Performance for meaningful stimuli $(M=1.73, S D=1.19)$ was higher than for meaningless stimuli $(M=1.14, S D=0.83)$. Younger adults performed higher $(M=1.78, S D=1.13)$ than older adults $(M=1.09, S D=0.88)$. Also, an interaction effect was found between sentence structure and meaning, $F(1,51)=45.29, p=$ $1.46 \times 10^{-8}, \eta^{2}=.11$. A simple effects analysis (Bonferronicorrected) showed that while performance was significantly higher for meaningful sentences $(M=2.55, S D=1.03)$ than for meaningless sentences $(M=1.48, S D=0.94) ; t(102)=-10.36, p=$ $5.11 \times 10^{-17}$, this performance difference was not present for meaningful lists $(M=0.90, S D=0.62)$ compared with meaningless lists $(M=0.80, S D=0.51) ; t(102)=-0.95, p=1.00$. Moreover, it showed a performance advantage for sentences over word lists, with real words, $t(99)=-14.65, p=6.43 \times 10^{-26}$ and also with pseudowords, $t(99)=-6.03, p=1.14 \times 10^{-7}$, indicating a sentence superiority effect independent of meaning. A direct comparison corroborated the suggested larger sentence superiority effect for meaningful (mean $d^{\prime}$ difference $=1.66, S D=$ $0.85)$ compared with meaningless stimuli (mean $d^{\prime}$ difference $=$ $0.68, S D=0.87) ; t(52)=6.78, p=1.11 \times 10^{-8}$. In contrast to

Table 4

Experiment 2, Example of Stimulus Material: Meaningful Sentences (Structure+, Meaning+), Meaningful Word Lists (Structure-, Meaning+), Meaningless Sentences (Structure+, Meaning-), and Meaningless Word Lists (Structure-, Meaning-)

\begin{tabular}{lll}
\hline \multirow{2}{*}{ Meaning } & \multicolumn{1}{c}{ Sentences } \\
\cline { 2 - 4 } Real words & $\begin{array}{l}\text { der Opa verdarb die Suppe mit dem Salz trotz des Rezepts } \\
\text { the granddad ruined the soup with the salt despite the recipe }\end{array}$ & $\begin{array}{l}\text { der verdarb des mit Suppe dem trotz Salz die Opa Rezepts } \\
\text { the ruined the with soup the despite salt the granddad recipe } \\
\text { Pseudowords }\end{array}$ \\
$\begin{array}{l}\text { der Apo verworb die Junne mit dem Sohr trotz des Rezerms } \\
\text { the Apo verworb the Junne with the Sohr despite the Rezerms }\end{array}$ & $\begin{array}{l}\text { der verb des mit Junne dem trotz Sohr die Apo Rezerms the with Junne the despite Sohr the Apo Rezerms } \\
\text { the }\end{array}$
\end{tabular}




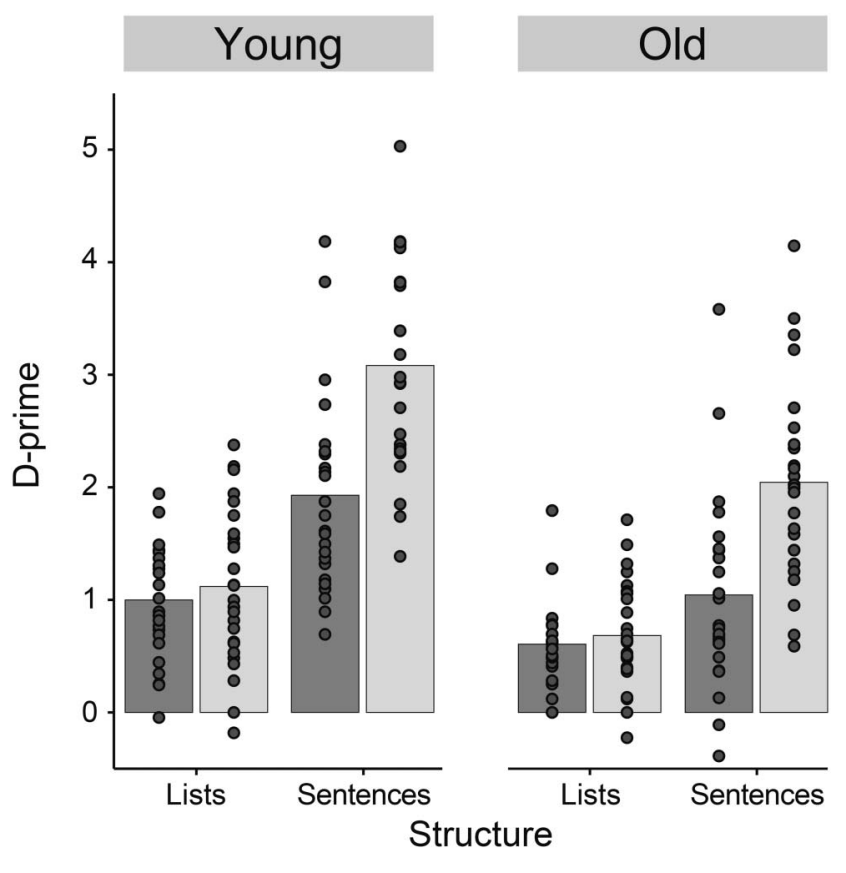

Meaning: $\quad \square$ Pseudowords $\quad \square$ Real words

Figure 2. Experiment 2, significant age differences in syntactic (sentences vs. lists) but not semantic (real words vs. pseudowords) processing.

Experiment 1, the interaction between sentence structure and age group was clearly significant, $F(1,51)=9.88, p=2.79 \times 10^{-3}$, $\eta^{2}=.04$. Simple effects analysis showed that while performance for sentences was significantly better for younger adults $(M=$ $2.51, S D=1.06)$ than older adults $(M=1.54, S D=0.98) ; t(84)=$ $5.70, p=6.93 \times 10^{-7}$, performance for lists did not differ between younger adults $(M=1.06, S D=0.65)$ and older adults $(M=0.65, S D=0.45) ; t(84)=2.46, p=.06$. In addition, it was found that both age groups showed a performance advantage of sentences over lists, young: $t(51)=11.64, p=2.29 \times 10^{-15}$; old: $t(51)=7.37, p=5.63 \times 10^{-9}$. However, the performance advantage for sentences over word lists was larger in younger (mean $d^{\prime}$ difference $=1.27, S D=0.62$ ) than in older adults (mean $d^{\prime}$ difference $\left.=0.82, S D=0.63\right) ; t(51)=2.65, p=.01$. No other effects were significant (all $F<0.43$, all $p>.51$ ).

To assess individual differences, particularly across age groups, we included the vWM composite score as between-subjects covariate into an ANCOVA (for an overview of vWM measures, see Table 1). The results revealed the same main effects for structure, $F(1,50)=188.44, p=2.20 \times 10^{-16}, \eta^{2}=.43$; meaning, $F(1$, $50)=63.57, p=1.83 \times 10^{-10}, \eta^{2}=.07$; and age group, $F(1$, $50)=12.57, p=8.61 \times 10^{-3}, \eta^{2}=.11$; as well as the same interaction effect between structure and meaning, $F(1,50)=$ $46.87, p=1.05 \times 10^{-8}, \eta^{2}=.12$. However, the effect size of the interaction between age group and structure was reduced, $F(1$, $50)=5.01, p=.03, \eta^{2}=.02$; yet, the interaction remained statistically significant, indicating a small disadvantage in sentence processing for older compared with younger adults. Remarkably, this age difference goes beyond the domain-general cognitive abilities as indexed by the present set of tasks. No other effects were significant (all $F>2.58$, all $p<.11$ ). Finally, the additional, post hoc analysis assessing predictability effects revealed that neither syntactic (median rho across participants $=0.09$, $\mathrm{Q} 1=-0.13, \mathrm{Q} 3=0.25$, all FDR-corrected $p>.76$ ) nor lexical probabilities (median $r h o$ across participants $=0.10, \mathrm{Q} 1=-0.14$, $\mathrm{Q} 3=0.29$, all FDR-corrected $p>$.77) could explain the role of the availability of syntactic and semantic constraints for chunking, respectively.

\section{General Discussion}

Our study reveals age differences in the use of syntactic and semantic constraints for chunking during sentence processing to reduce $\mathrm{vWM}$ demands. The results indicate that the availability of syntactic constraints, which enables syntactic chunking (Bonhage et al., 2017; Zaccarella, Meyer, Makuuchi, \& Friederici, 2017), is somewhat less beneficial for older than younger adults (e.g., Feier \& Gerstman, 1980; Kemper, 1987; Obler et al., 1991; StineMorrow, Ryan, \& Leonard, 2000)—particularly when sentences are longer (Experiment 2) but not when sentences are shorter (Experiment 1). Moreover, this age difference persisted even when vWM capacity was accounted for: Older adults displayed a disadvantage in the processing of longer sentences. This indicates difficulties in domain-specific beyond domain-general cognitive abilities. In comparison, we did not find any evidence for an increased recruitment of semantic information in older compared with younger adults. Hence, the benefit of the availability of semantic constraints was comparable across age. Moreover, both age groups showed an advantage of processing meaningful over meaningless sentences, but not lists-increasing the sentence superiority effect by meaningful relations between real words for both age groups.

In general, it is clear that allocating resources to the decoding of syntactic regularities in order to chunk sentences reduces vWM costs-also in the aging population (as indicated by Wingfield, Tun, \& Rosen, 1995). Our results, however, suggest that the chunking benefit is reduced in older adults, reflected by a lower benefit of the availability of syntactic regularities when vWM demands are high (Experiment 2). More precisely, only sentences where syntactic regularities were present, but not word lists where syntactic regularities were absent, were remembered less by older than younger adults, suggesting age differences in the sentence superiority effect, in particular in the use of syntactic constraints (as supported by another line of research Craik \& Masani, 1967; Gilchrist et al., 2008). This effect was present in spite of a potential emphasis of our serial order task on the memory for word orderand thereby syntactic rather than semantic constraints. While such emphasis could have biased the results toward better syntactic memory, our results suggest that this was apparently not the case. Age differences in syntactic processing persist even when a task focuses on the processing of syntactic constraints (e.g., Gao, Levinthal, \& Stine-Morrow, 2012; Stine-Morrow et al., 2010). Therefore, regardless of task-related processes, our results suggest that older adults do not benefit as much as younger adults from syntactic constraints to attenuate their vWM limitations during sentence processing.

Contributing to an ongoing debate, our results show age differences in syntactic processing (e.g., Just \& Carpenter, 1992; Kemper, 1986, 1987; Obler et al., 1991; Radvansky et al., 2001; 
Stine-Morrow et al., 2000), contrary to studies suggesting age preservation (e.g., Campbell et al., 2016; Caplan \& Waters, 1999; Davis, Zhuang, Wright, \& Tyler, 2014; Samu et al., 2017; Shafto \& Tyler, 2014; Tyler et al., 2010). According to the latter studies, older adults use syntactic structure for interpretive processing, despite age-related decrements in vWM capacity (Caplan \& Waters, 1999, 2013). However, unlike our study, those studies were restricted to semantically meaningful sentences. Thus, age differences in syntactic processing may have been attenuated or masked by semantic processes, which are known to be more stable across the life span (e.g., Laver, 2009). Yet, further research is needed to better understand these differences in results.

There are multiple potential explanations for a disadvantage in the use of syntactic constraints for chunking at old age. The most plausible explanation, for us, is that when processing demands increase, older adults allocate fewer resources to the decoding of syntactic regularities (Stine-Morrow et al., 1996); that is, their surface form representations fade away more quickly (e.g., Radvansky et al., 2001). As a consequence, older adults may process sentences in a "good-enough" manner (Amichetti et al., 2016; Christianson et al., 2006; Ferreira, 2003; Traxler, 2014), focusing on the situation, thereby extracting gist rather than detailed knowledge (Tun, Wingfield, Rosen, \& Blanchard, 1998). Age differences in the reliance on this processing heuristic appears to persist even when the task context puts particular emphasis on enriched sentence processing (Stine-Morrow et al., 2010), as was the case for the serial order judgment in the present study. Good-enough sentence processing has been proposed to lead to incomplete and shallow representations of syntactic and semantic information (Ferreira \& Patson, 2007). The depth to which these representations are processed is associated with the degree of cognitive analysis: higher levels of processing create stronger memory traces (Craik \& Lockhart, 1972; Craik \& Tulving, 1975). Hence, it is possible that the disadvantage in using syntactic constraints for chunking may arise because good-enough sentence processing leads to shallow representations of syntactic regularities that constitute the basis for the chunking mechanism. If fewer resources are allocated to syntactic regularities, thereby creating goodenough rather than detailed syntactic representations, the binding process may become deficient. To this end, binding may be understood as the core basis of chunking: Single elements can be bound into chunks through their strong associations with each other. In support of this hypothesis, it is well known that older adults are generally deficient in binding information to larger entities (Chalfonte \& Johnson, 1996; Fandakova, Sander, WerkleBergner, \& Shing, 2014; Mitchell, Johnson, Raye, \& D'Esposito, 2000; Sander, Lindenberger, \& Werkle-Bergner, 2012; Sander, Werkle-Bergner, \& Lindenberger, 2011; Shing et al., 2010). Our results showed a smaller processing advantage of sentences over lists in older than younger adults, possibly indicating that goodenough processing of syntactic constraints may be insufficient for proper syntactic chunking.

As an alternative to the good-enough processing hypothesis, it is also possible that the diminished advantage of processing sentences over lists, particularly in the more resource-demanding Experiment 2, resulted from an overload of older adults' vWM capacity associated with increased supraspan interference (Craik \& Masani, 1967; Melton, 1963; Wingfield et al., 1995). During sentence processing, supraspan interference can occur when capacity limits are exceeded and syntactic features start to interfere with each other. The ability to suppress interference is a critical determinant of successful sentence comprehension (Glaser, Martin, Van Dyke, Hamilton, \& Tan, 2013; Lewis et al., 2006; Santi, Friederici, Makuuchi, \& Grodzinsky, 2015; Van Dyke, 2007). Gilchrist et al. (2008) observed that recall performance declined in older adults with increasing number of chunks, particularly so in longer compared with shorter sentences. Similarly, in our study, older adults' performance was particularly compromised relative to younger adults when sentences were longer (Experiment 2). Therefore, reduced vWM capacity in older compared with younger adults may be associated with increased supraspan interference during sentence processing (Craik \& Masani, 1967; Hasher \& Zacks, 1988). However, our results do not support this theory given that vWM capacity differences alone cannot explain the age differences in syntactic chunking: When age-related differences in vWM capacity were accounted for, older adults' disadvantage in syntactic chunking remained considerable. Nonetheless, supraspan interference may not only be subject to vWM capacity limitations but also to age-related differences in the general ability to inhibit interfering material (Hasher \& Zacks, 1988). Therefore, future studies should capture the influence of supraspan interference by using additional tasks like the Stroop (Stroop, 1935) or flanker task (Eriksen \& Eriksen, 1974).

A third possibility for age differences in the ability to use syntactic constraints for chunking is that older adults may have more difficulties than younger adults in using (syntactic) templates (Charness, 1981; for an overview of template theory, see Gobet \& Simon, 1996). Syntactic relationships may be represented as templates, providing structures with fixed slots that have to be filled with variable information (Van Valin \& LaPolla, 1997). It is presumed that with experience single elements do not have to be repeatedly chunked into larger entities but at one point can be stored as larger chunks (Gobet \& Simon, 1996), like a reoccurring sequence of word categories building a common phrase structure. These common phrase structures may then function as templates. Templates, in general, are thought to be stored in long-term memory (LTM, Gobet \& Simon, 1996; Guida, Gobet, Tardieu, \& Nicolas, 2012). With syntactic processing being rather automatic, syntactic templates may constitute an implicit, procedural-like long-term memory. Both implicit and procedural memories are relatively spared from age-related decline (e.g., Mitchell, Brown, \& Murphy, 1990). Moreover, in our study, we used the same syntactic structure for all sentences. Therefore, a disadvantage in the use of syntactic regularities for chunking is most likely not associated with difficulties in using (the same) syntactic templates (over and over again). However, further research is needed to examine the various options and tackle the specificities of the disadvantage in syntactic chunking.

While the results showed that older adults do not benefit from syntactic constraints as much as younger adults, older adults showed a similar advantage in the use of semantic information when available. That is, younger and older adults both remembered meaningful words better than meaningless pseudowords. This may seem contrary to prior findings showing that older adults have greater difficulties than younger adults in recoding meaningful compared with meaningless words (e.g., Heron \& Craik, 1964). 
However, our findings additionally show that the advantage in the use of available semantic information was increased in the presence of syntactic constraints. That is, both age groups took advantage of the semantic information of words, in particular when the words were also syntactically related. Therefore, our findings may relate to an enrichment of lexical-semantic representations by relational semantics. This result substantiates theories indicating a role of meaningfulness to syntactic chunking (e.g., Tulving \& Patkau, 1962) while refuting the position that there is no interaction between sentence structure and meaningfulness (e.g., Epstein, 1962). In light of age differences in syntactic chunking, the intact ability of semantic processing may become relatively more salient for sentence processing at old age. Therefore, older adults may change their sentence processing strategy toward a semantic approach (Amichetti et al., 2016). However, further research is needed to substantiate this suggestion.

\section{Conclusion}

Our study suggests that sentence processing is facilitated by both the ability to use syntactic constraints for chunking and the availability of semantic information. While both younger and older adults profit from semantic information to a similar extent, the benefit of using syntactic constraints for chunking decreases with normal aging. Hence, the relative importance of semantic information processing is increased for successful language comprehension in old age. This finding persisted even when individual differences in vWM capacity were accounted for, pointing to a disadvantage in language-specific beyond domain-general cognitive abilities in old age. The salience of semantic information may lead to a change in sentence processing strategies toward a semantic approach later in life. Further research endeavors are needed to support this hypothesis.

\section{References}

Amichetti, N. M., White, A. G., \& Wingfield, A. (2016). Multiple solutions to the same problem: Utilization of plausibility and syntax in sentence comprehension by older adults with impaired hearing. Frontiers in Psychology, 7, 789. http://dx.doi.org/10.3389/fpsyg.2016.00789

Aster, M. V., Neubauer, A., \& Horn, R. (Eds.). (2006). Wechsler Intelligenztest für Erwachsene [Wechsler Adult Intelligence Scale]. Frankfurt, Germany: Pearson Assessment.

Baddeley, A. D., Hitch, G. J., \& Allen, R. J. (2009). Working memory and binding in sentence recall. Journal of Memory and Language, 61, 438-456. http://dx.doi.org/10.1016/j.jml.2009.05.004

Beese, C., Meyer, L., Vassileiou, B., \& Friederici, A. D. (2017). Temporally and spatially distinct theta oscillations dissociate a languagespecific from a domain-general processing mechanism across the age trajectory. Scientific Reports, 7, 11202. http://dx.doi.org/10.1038/ s41598-017-11632-z

Bierwisch, M., \& Schreuder, R. (1992). From concepts to lexical items. Cognition, 42, 23-60. http://dx.doi.org/10.1016/0010-0277(92)90039-K

Bonhage, C. E., Fiebach, C. J., Bahlmann, J., \& Mueller, J. L. (2014). Brain signature of working memory for sentence structure: Enriched encoding and facilitated maintenance. Journal of Cognitive Neuroscience, 26, 1654-1671. http://dx.doi.org/10.1162/jocn_a_00566

Bonhage, C. E., Meyer, L., Gruber, T., Friederici, A. D., \& Mueller, J. L. (2017). Oscillatory EEG dynamics underlying automatic chunking during sentence processing. NeuroImage, 152, 647-657. http://dx.doi.org/ 10.1016/j.neuroimage.2017.03.018
Bonin, P., Gelin, M., \& Bugaiska, A. (2014). Animates are better remembered than inanimates: Further evidence from word and picture stimuli. Memory \& Cognition, 42, 370-382. http://dx.doi.org/10.3758/s13421013-0368-8

Bopp, K. L., \& Verhaeghen, P. (2005). Aging and verbal memory span: A meta-analysis. Journal of Gerontology: Psychological Sciences and Social sciences, 60, 223-233.

Brants, S., Dipper, S., Eisenberg, P., Hansen-Schirra, S., König, E., Lezius, W., . . . Uszkoreit, H. (2004). TIGER: Linguistic interpretation of a German corpus. Research on Language and Computation, 2, 597-620. http://dx.doi.org/10.1007/s11168-004-7431-3

Brennan, J., Nir, Y., Hasson, U., Malach, R., Heeger, D. J., \& Pylkkänen, L. (2012). Syntactic structure building in the anterior temporal lobe during natural story listening. Brain and Language, 120, 163-173. http://dx.doi.org/10.1016/j.bandl.2010.04.002

Burke, D. M., White, H., \& Diaz, D. L. (1987). Semantic priming in young and older adults: Evidence for age constancy in automatic and attentional processes. Journal of Experimental Psychology: Human Perception and Performance, 13, 79-88. http://dx.doi.org/10.1037/0096-1523 .13 .1 .79

Campbell, K. L., Samu, D., Davis, S. W., Geerligs, L., Mustafa, A., \& Tyler, L. K., \& the for Cambridge Centre for Aging and Neuroscience. (2016). Robust resilience of the frontotemporal syntax system to aging. The Journal of Neuroscience, 36, 5214-5227. http://dx.doi.org/10.1523/ JNEUROSCI.4561-15.2016

Caplan, D., \& Waters, G. S. (1999). Verbal working memory and sentence comprehension. Behavioral and Brain Sciences, 22, 77-94. http://dx.doi .org/10.1017/S0140525X99001788

Caplan, D., \& Waters, G. (2013). Memory mechanisms supporting syntactic comprehension. Psychonomic Bulletin \& Review, 20, 243-268. http://dx.doi.org/10.3758/s13423-012-0369-9

Cattell, J. (1886). The time it takes to see and name objects. Mind, 11, 63-65. http://dx.doi.org/10.1093/mind/os-XI.41.63

Chalfonte, B. L., \& Johnson, M. K. (1996). Feature memory and binding in young and older adults. Memory \& Cognition, 24, 403-416. http:// dx.doi.org/10.3758/BF03200930

Charness, N. (1981). Aging and skilled problem solving. Journal of Experimental Psychology: General, 110, 21-38. http://dx.doi.org/10.1037/ 0096-3445.110.1.21

Christianson, K., Williams, C. C., Zacks, R. T., \& Ferreira, F. (2006). Younger and older adults' "good-enough" interpretations of garden-path sentences. Discourse Processes, 42, 205-238. http://dx.doi.org/10.1207/ s15326950dp4202_6

Craik, F. I. M., \& Lockhart, R. S. (1972). Levels of processing: A framework for memory research. Journal of Verbal Learning \& Verbal Behavior, 11, 671-684. http://dx.doi.org/10.1016/S0022-5371(72) 80001-X

Craik, F. I., \& Masani, P. A. (1967). Age differences in the temporal integration of language. British Journal of Psychology, 58, 291-299. http://dx.doi.org/10.1111/j.2044-8295.1967.tb01086.x

Craik, F. I. M., \& Tulving, E. (1975). Depth of processing and the retention of words. Journal of Experimental Psychology: General, 104, 268-294. http://dx.doi.org/10.1037/0096-3445.104.3.268

Davis, S. W., Zhuang, J., Wright, P., \& Tyler, L. K. (2014). Age-related sensitivity to task-related modulation of language-processing networks. Neuropsychologia, 63, 107-115. http://dx.doi.org/10.1016/j.neuropsychologia.2014.08.017

Epstein, W. (1962). A further study of the influence of syntactical structure on learning. The American Journal of Psychology, 75, 121-126. http:// dx.doi.org/10.2307/1419550

Eriksen, B. A., \& Eriksen, C. W. (1974). Effects of noise letters upon identification of a target letter in a non-search task. Perception \& Psychophysics, 16, 143-149. http://dx.doi.org/10.3758/BF03203267 
Fandakova, Y., Sander, M. C., Werkle-Bergner, M., \& Shing, Y. L. (2014). Age differences in short-term memory binding are related to working memory performance across the lifespan. Psychology and Aging, 29, 140-149. http://dx.doi.org/10.1037/a0035347

Feier, C. D., \& Gerstman, L. J. (1980). Sentence comprehension abilities throughout the adult life span. Journal of Gerontology, 35, 722-728. http://dx.doi.org/10.1093/geronj/35.5.722

Ferreira, F. (2003). The misinterpretation of noncanonical sentences. Cognitive Psychology, 47, 164-203. http://dx.doi.org/10.1016/S00100285(03)00005-7

Ferreira, F., \& Patson, N. D. (2007). The "good enough" approach to language comprehension. Language and Linguistics Compass, 1, 71-83. http://dx.doi.org/10.1111/j.1749-818X.2007.00007.x

Freudenthal, D., Pine, J. M., Aguado-Orea, J., \& Gobet, F. (2007). Modeling the developmental patterning of finiteness marking in English, Dutch, German, and Spanish using MOSAIC. Cognitive Science, 31, 311-341.

Friederici, A. D., Schriefers, H., \& Lindenberger, U. (1998). Differential age effects on semantic and syntactic priming. International Journal of Behavioral Development, 22, 813-845. http://dx.doi.org/10.1080/ 016502598384180

Gao, X., Levinthal, B. R., \& Stine-Morrow, E. A. (2012). The effects of ageing and visual noise on conceptual integration during sentence reading. Quarterly Journal of Experimental Psychology, 65, 1833-1847. http://dx.doi.org/10.1080/17470218.2012.674146

Gibson, E. (2000). The dependency locality theory: A distance-based theory of linguistic complexity. In Y. Miyashita, A. Marantz, \& W. O’Neil (Eds.), Image, language, brain (pp. 95-126). Cambridge, MA: MIT Press.

Gilchrist, A. L. (2015). How should we measure chunks? A continuing issue in chunking research and a way forward. Frontiers in Psychology, 6, 1456. http://dx.doi.org/10.3389/fpsyg.2015.01456

Gilchrist, A. L., \& Cowan, N. (2012). Chunking. In V. S. Ramachandran (Ed.), Encyclopedia of behavior (2nd ed., Vol. 1, pp. 476-483). San Diego, CA: Academic Press. http://dx.doi.org/10.1016/B978-0-12375000-6.00089-6

Gilchrist, A. L., Cowan, N., \& Naveh-Benjamin, M. (2008). Working memory capacity for spoken sentences decreases with adult ageing: Recall of fewer but not smaller chunks in older adults. Memory, 16, 773-787. http://dx.doi.org/10.1080/09658210802261124

Glaser, Y. G., Martin, R. C., Van Dyke, J. A., Hamilton, A. C., \& Tan, Y. (2013). Neural basis of semantic and syntactic interference in sentence comprehension. Brain and Language, 126, 314-326. http://dx.doi.org/ 10.1016/j.bandl.2013.06.006

Gobet, F., Lane, P. C., Croker, S., Cheng, P. C., Jones, G., Oliver, I., \& Pine, J. M. (2001). Chunking mechanisms in human learning. Trends in Cognitive Sciences, 5, 236-243. http://dx.doi.org/10.1016/S13646613(00)01662-4

Gobet, F., Lane, P. C., \& Lloyd-Kelly, M. (2015). Chunks, schemata, and retrieval structures: Past and current computational models. Frontiers in Psychology, 6, 1785. http://dx.doi.org/10.3389/fpsyg.2015.01785

Gobet, F., Lloyd-Kelly, M., \& Lane, P. C. (2016). What's in a name? The multiple meanings of "chunk" and "chunking." Frontiers in Psychology, 7, 102. http://dx.doi.org/10.3389/fpsyg.2016.00102

Gobet, F., \& Simon, H. A. (1996). Templates in chess memory: A mechanism for recalling several boards. Cognitive Psychology, 31, 1-40. http://dx.doi.org/10.1006/cogp.1996.0011

Goldhahn, D., Eckart, T., \& Quasthoff, U. (2012, May). Building large monolingual dictionaries at the Leipzig Corpora Collection: From 100 to 200 languages. Paper presented at the Proceedings of the Eighth International Conference on Language Resources and Evaluation, Istanbul, Turkey.

Guida, A., Gobet, F., Tardieu, H., \& Nicolas, S. (2012). How chunks, long-term working memory and templates offer a cognitive explanation for neuroimaging data on expertise acquisition: A two-stage framework. Brain and Cognition, 79, 221-244. http://dx.doi.org/10.1016/j.bandc 2012.01.010

Gunter, T. C., Jackson, J. L., \& Mulder, G. (1998). Priming and aging: An electrophysiological investigation of N400 and recall. Brain and Language, 65, 333-355. http://dx.doi.org/10.1006/brln.1998.1987

Hale, J. (2001, June). A probabilistic earley parser as a psycholinguistic model. Proceedings of the second meeting of the North American chapter of the Association for Computational Linguistics on Language technologies, Pittsburgh, Pennsylvania.

Halgren, E., Dhond, R. P., Christensen, N., Van Petten, C., Marinkovic, K., Lewine, J. D., \& Dale, A. M. (2002). N400-like magnetoencephalography responses modulated by semantic context, word frequency, and lexical class in sentences. NeuroImage, 17, 1101-1116. http://dx.doi org/10.1006/nimg.2002.1268

Hasher, L., \& Zacks, R. T. (1988). Working memory, comprehension, and aging: A review and a new view. In G. H. Bower (Ed.), The psychology of learning and motivation (Vol. 22, pp. 193-225). New York, NY: Academic Press. http://dx.doi.org/10.1016/S0079-7421(08)60041-9

Heron, A., \& Craik, F. (1964). Age differences in cumulative learning of meaningful and meaningless material. Scandinavian Journal of Psychology, 5, 209-217. http://dx.doi.org/10.1111/j.1467-9450.1964.tb01426.x

Johnson, N. F. (1978). The memorial structure of organized sequences. Memory \& Cognition, 6, 233-239. http://dx.doi.org/10.3758/ $\mathrm{BF} 03197451$

Just, M. A., \& Carpenter, P. A. (1992). A capacity theory of comprehension: Individual differences in working memory. Psychological Review, 99, 122-149. http://dx.doi.org/10.1037/0033-295X.99.1.122

Kemper, S. (1986). Imitation of complex syntactic constructions by elderly adults. Applied Psycholinguistics, 7, 277-287. http://dx.doi.org/10.1017/ S0142716400007578

Kemper, S. (1987). Syntactic complexity and elderly adults' prose recall. Experimental Aging Research, 13, 47-52. http://dx.doi.org/10.1080/ 03610738708259299

Kemper, S., Crow, A., \& Kemtes, K. (2004). Eye-fixation patterns of highand low-span young and older adults: Down the garden path and back again. Psychology and Aging, 19, 157-170. http://dx.doi.org/10.1037/ 0882-7974.19.1.157

Keuleers, E., \& Brysbaert, M. (2010). Wuggy: A multilingual pseudoword generator. Behavior Research Methods, 42, 627-633. http://dx.doi.org/ 10.3758/BRM.42.3.627

Kintsch, W., Welsch, D., Schmalhofer, F., \& Zimny, S. (1990). Sentence memory: A theoretical analysis. Journal of Memory and Language, 29, 133-159. http://dx.doi.org/10.1016/0749-596X(90)90069-C

Laver, G. D. (2009). Adult aging effects on semantic and episodic priming in word recognition. Psychology and Aging, 24, 28-39. http://dx.doi .org/10.1037/a0014642

Lewis, R. L., Vasishth, S., \& Van Dyke, J. A. (2006). Computational principles of working memory in sentence comprehension. Trends in Cognitive Sciences, 10, 447-454. http://dx.doi.org/10.1016/j.tics.2006 .08 .007

Leys, C., Ley, C., Klein, O., Bernard, P., \& Licata, L. (2013). Detecting outliers: Do not use standard deviation around the mean, use absolute deviation around the median. Journal of Experimental Social Psychology, 49, 764-766. http://dx.doi.org/10.1016/j.jesp.2013.03.013

Macmillan, N. A., \& Creelman, C. D. (2005). Detection theory: A user's guide (2nd ed.). New York, NY: Erlbaum.

Melton, A. W. (1963). Memory. Science, 140, 82-86. http://dx.doi.org/10 $.1126 /$ science. 140.3562 .82

Meyer, L., \& Gumbert, M. (2018). Synchronization of electrophysiological responses with Speech Benefits Syntactic Information Processing. Journal of Cognitive Neuroscience, 30, 1066-1074. 
Meyer, L., Henry, M. J., Gaston, P., Schmuck, N., \& Friederici, A. D. (2017). Linguistic bias modulates interpretation of speech via neural delta-band oscillations. Cerebral Cortex, 27, 4293-4302.

Meyer, L., Obleser, J., Kiebel, S. J., \& Friederici, A. D. (2012). Spatiotemporal dynamics of argument retrieval and reordering: An FMRI and EEG study on sentence processing. Frontiers in Psychology, 3, 523. http://dx.doi.org/10.3389/fpsyg.2012.00523

Miller, G. A. (1956). The magical number seven plus or minus two: Some limits on our capacity for processing information. Psychological Review, 63, 81-97. http://dx.doi.org/10.1037/h0043158

Mitchell, D. B., Brown, A. S., \& Murphy, D. R. (1990). Dissociations between procedural and episodic memory: Effects of time and aging. Psychology and Aging, 5, 264-276. http://dx.doi.org/10.1037/08827974.5.2.264

Mitchell, K. J., Johnson, M. K., Raye, C. L., \& D'Esposito, M. (2000). fMRI evidence of age-related hippocampal dysfunction in feature binding in working memory. Cognitive Brain Research, 10, 197-206. http:// dx.doi.org/10.1016/S0926-6410(00)00029-X

Obler, L. K., Fein, D., Nicholas, M., \& Albert, M. L. (1991). Auditory comprehension and aging: Decline in syntactic processing. Applied Psycholinguistics, 12, 433-452. http://dx.doi.org/10.1017/S01427164 00005865

Radvansky, G. A. (1999). Aging, memory and comprehension. Current Directions in Psychological Science, 8, 49-53. http://dx.doi.org/10 $.1111 / 1467-8721.00012$

Radvansky, G. A., Curiel, J. M., Zwaan, R. A., \& Copeland, D. E. (2001). Situation models and aging. Psychology and Aging, 16, 145-160. http:// dx.doi.org/10.1037/0882-7974.16.1.145

Radvansky, G. A., \& Dijkstra, K. (2007). Aging and situation model processing. Psychonomic Bulletin \& Review, 14, 1027-1042. http://dx .doi.org/10.3758/BF03193088

Reicher, G. M. (1969). Perceptual recognition as a function of meaningfulness of stimulus material. Journal of Experimental Psychology, 81, 275-280. http://dx.doi.org/10.1037/h0027768

Roark, B., Bachrach, A., Cardenas, C., \& Pallier, C. (2009, August). Deriving lexical and syntactic expectation-based measures for psycholinguistic modeling via incremental top-down parsing. Proceedings of the 2009 Conference on Empirical Methods in Natural Language Processing, Singapore.

Sachs, J. S. (1967). Recognition memory for syntactic and semantic aspects of connected discourse. Perception \& Psychophysics, 2, 437-442. http:// dx.doi.org/10.3758/BF03208784

Salthouse, T. A. (1994). The aging of working memory. Neuropsychology, 8, 535-543. http://dx.doi.org/10.1037/0894-4105.8.4.535

Samu, D., Campbell, K. L., Tsvetanov, K. A., Shafto, M. A., Tyler, L. K., \& Tyler, L. K., \& the Cam-CAN consortium. (2017). Preserved cognitive functions with age are determined by domain-dependent shifts in network responsivity. Nature Communications, 8, 14743. http://dx.doi .org/10.1038/ncomms 14743

Sander, M. C., Lindenberger, U., \& Werkle-Bergner, M. (2012). Lifespan age differences in working memory: A two-component framework. Neuroscience and Biobehavioral Reviews, 36, 2007-2033. http://dx.doi .org/10.1016/j.neubiorev.2012.06.004

Sander, M. C., Werkle-Bergner, M., \& Lindenberger, U. (2011). Binding and strategic selection in working memory: A lifespan dissociation. Psychology and Aging, 26, 612-624. http://dx.doi.org/10.1037/ a0023055

Santi, A., Friederici, A. D., Makuuchi, M., \& Grodzinsky, Y. (2015). An fMRI study dissociating distance measures computed by Broca's area in movement processing: Clause boundary vs. identity. Frontiers in Psychology, 6, 654. http://dx.doi.org/10.3389/fpsyg.2015.00654

Schell, M., Zaccarella, E., \& Friederici, A. D. (2017). Differential cortical contribution of syntax and semantics: An fMRI study on two-word phrasal processing. Cortex: A Journal Devoted to the Study of the
Nervous System and Behavior, 96, 105-120. http://dx.doi.org/10.1016/j cortex.2017.09.002

Shafto, M. A., \& Tyler, L. K. (2014). Language in the aging brain: The network dynamics of cognitive decline and preservation. Science, 346 583-587. http://dx.doi.org/10.1126/science. 1254404

Shing, Y. L., Werkle-Bergner, M., Brehmer, Y., Müller, V., Li, S. C., \& Lindenberger, U. (2010). Episodic memory across the lifespan: The contributions of associative and strategic components. Neuroscience and Biobehavioral Reviews, 34, 1080-1091. http://dx.doi.org/10.1016/j neubiorev.2009.11.002

Snell, J., \& Grainger, J. (2017). The sentence superiority effect revisited. Cognition, 168, 217-221. http://dx.doi.org/10.1016/j.cognition.2017.07 .003

Spoehr, K. T., \& Smith, E. E. (1973). The role of syllables in perceptual processing. Cognitive Psychology, 5, 71-89. http://dx.doi.org/10.1016/ 0010-0285(73)90026-1

Stine, E. A. (1990). On-line processing of written text by younger and older adults. Psychology and Aging, 5, 68-78. http://dx.doi.org/10.1037/08827974.5.1.68

Stine-Morrow, E. A., Loveless, M. K., \& Soederberg, L. M. (1996). Resource allocation in on-line reading by younger and older adults. Psychology and Aging, 11, 475-486. http://dx.doi.org/10.1037/08827974.11.3.475

Stine-Morrow, E. A., Noh, S. R., \& Shake, M. C. (2010). Age differences in the effects of conceptual integration training on resource allocation in sentence processing. Quarterly Journal of Experimental Psychology, 63 1430-1455. http://dx.doi.org/10.1080/17470210903330983

Stine-Morrow, E. A., \& Payne, B. R. (2016). Age differences in language segmentation. Experimental Aging Research, 42, 83-96. http://dx.do org/10.1080/0361073X.2016.1108751

Stine-Morrow, E. A., Ryan, S., \& Leonard, J. S. (2000). Age differences in on-line syntactic processing. Experimental Aging Research, 26, 315322. http://dx.doi.org/10.1080/036107300750015714

Stroop, J. R. (1935). Studies of interference in serial verbal reactions. Journal of Experimental Psychology, 18, 643-662. http://dx.doi.org/10 $1037 / \mathrm{h} 0054651$

Traxler, M. J. (2014). Trends in syntactic parsing: Anticipation, Bayesian estimation, and good-enough parsing. Trends in Cognitive Sciences, 18, 605-611. http://dx.doi.org/10.1016/j.tics.2014.08.001

Tulving, E., \& Patkau, J. E. (1962). Concurrent effects of contextual constraint and word frequency on immediate recall and learning of verbal material. Canadian Journal of Psychology, 16, 83-95. http://dx .doi.org/10.1037/h0083231

Tun, P. A., Wingfield, A., Rosen, M. J., \& Blanchard, L. (1998). Response latencies for false memories: Gist-based processes in normal aging. Psychology and Aging, 13, 230-241. http://dx.doi.org/10.1037/08827974.13.2.230

Tyler, L. K., Shafto, M. A., Randall, B., Wright, P., Marslen-Wilson, W. D., \& Stamatakis, E. A. (2010). Preserving syntactic processing across the adult life span: The modulation of the frontotemporal language system in the context of age-related atrophy. Cerebral Cortex, 20, 352-364. http://dx.doi.org/10.1093/cercor/bhp105

Van Dyke, J. A. (2007). Interference effects from grammatically unavailable constituents during sentence processing. Journal of Experimental Psychology: Learning, Memory, and Cognition, 33, 407-430. http://dx doi.org/10.1037/0278-7393.33.2.407

Van Valin, R. D., \& LaPolla, R. J. (1997). Syntax: Structure, meaning, and function. New York, NY: Cambridge University Press. http://dx.doi.org/ 10.1017/CBO9781139166799

Welte, V. (1981). Der Mottier-Test, ein Prüfmittel für die Lautdifferenzierungsfähigkeit und die auditive Merkfähigkeit [The Mottier test, a tool for the assessment of phoneme discrimination and auditory memory capacity]. Sprache, Stimme, Gehör, 5, 121-125. 
Wingfield, A., Poon, L. W., Lombardi, L., \& Lowe, D. (1985). Speed of processing in normal aging: Effects of speech rate, linguistic structure, and processing time. Journal of Gerontology, 40, 579-585. http://dx.doi .org/10.1093/geronj/40.5.579

Wingfield, A., Tun, P. A., \& Rosen, M. J. (1995). Age differences in veridical and reconstructive recall of syntactically and randomly segmented speech. The Journals of Gerontology: Series B: Psychological Sciences and Social Sciences, 50, 257-266. http://dx.doi.org/10.1093/ geronb/50B.5.P257
Zaccarella, E., Meyer, L., Makuuchi, M., \& Friederici, A. D. (2017). Building by syntax: The neural basis of minimal linguistic structures. Cerebral Cortex, 27, 411-421.

\section{P. Amercan Psrchological Assoclation \\ APA JOURNALS}

\section{ORDER INFORMATION}

Start my 2019 subscription to

Psychology and Aging ${ }^{\circledR}$

ISSN: 0882-7974

\section{PRICING}

APA Member/Affiliate $\$ 131$

Individual Nonmember \$271

Institution \$992

Call 800-374-2721 or 202-336-5600

Fax 202-336-5568 | TDD/TTY 202-336-6123

Subscription orders must be prepaid. Subscriptions are on a calendar year basis. Please allow 4-6 weeks for delivery of the first issue.

Learn more and order online at: www.apa.org/pubs/journals/pag

\section{Visit on.apa.org/circ2019 to browse APA's full journal collection.}

All APA journal subscriptions include online first journal articles and access to archives. Individuals can receive online access to all of APA's 88 scholarly journals through a subscription to APA PsycNET ${ }^{\circledR}$, or through an institutional subscription to the PsycARTICLES ${ }^{\circledR}$ database. 